\title{
НЕГАТИВНЫЕ ОСОБЕННОСТИ И ПРОГНОЗНЫЕ ПОСЛЕДСТВИЯ ЦИФРОВОЙ ЭКОНОМИКИ НА РАЗВИТИЕ СОЦИАЛЬНОГО ОБЩЕСТВА
}

\section{NEGATIVE FEATURES AND PREDICTIVE EFFECTS OF THE DIGITAL ECONOMY ON THE DEVELOPMENT OF SOCIAL SOCIETY}

N. Vnukovsky

Summary. The article examines the main organizational and intellectual problematic issues of the digital economy of information support of the transport system of the Russian Federation. Certain negative consequences of the development of digitalization in various spheres of society on the economy and the level of quality of life of citizens are revealed.

Keywords: digital economy of the Russian Federation, digital transformation, problems and negatives of digitalization, digital tension, cybercrime.

\author{
Внуковский Николай Иванович \\ Д.э.н., профессор, Уральский государственный \\ университет путей сообщения, г. Екатеринбург \\ vnukovsk@ya.ru
}

Аннотация. В статье исследованы основные организационно-интеллектуальные проблемные вопросы цифровой экономики информационного обеспечения транспортной системы российской федерации. Выявлены определенные негативные последствия развития цифровизации в различных сферах общества на экономику и уровень качества жизни граждан.

Ключевые слова: цифровая экономика РФ, цифровая трансформация, проблемы и негативы цифровизации, цифровая напряженность, киберпреступHость.

с внешним окружением: поставщиками, производителями продукции и услуг и, конечно, с частной личной жизнью каждого человека, о которой банкам и компаниям нужно знать подробно и все. Сегодня каждый индивидуум в цифровом обществе оставляет цифровые следы, по которым его легко вычислить, если он пытается что-либо утаить или нарушить установленные правила, законодательство. В результате на каждого будет создаваться досье для контроля за конкретной личностью, например, в аэропортах, в зарубежных поездках и др. [6-8].

Таким образом, происходит использование персональных данных множества людей, их обработка для возможного воздействия в дальнейшем на их поведение в общественной жизни общества $[5,8]$.

Сегодня в реалии изменяются отношения человека и цифрового мира. В частности, в борьбе за клиента современный маркетинг на оперативном уровне управления- это маркетинг «лохотронства», обмана с использованием психотехнического воздействия на клиента. Человек оказывается объектом манипулирования, поэтому и приобретает те услуги и продукты, которые навязывают ему предприниматели в соответствии с навязчивой нечестной рекламой и недобросовестных менеджеров, думающих в первую очередь как обмануть клиента и «набить себе карман», в виде вознаграждений по агентским соглашениям, а не об имидже данной фирмы, компании, банка и т.д. Например, банки заключают 
агентские соглашения со страховыми компаниями, типа «Ренесанс-жизнь», «Альфа-страхование» и другие, затем банки не объясняя клиентам условий данного договора навязывают данные договора в виде страхования жизни, в результате по своим инвестициям клиент чрез 3-5 лет по окончанию срока договора получает возврат только тех денежных средств, которые клиент вложил первоначально без начисления процентов по вкладу. Причем объясняют причину по отработанной технологии, что денежные средства были вложены в различные ценные бумаги и дохода никакого не получили. Когда делаешь запрос по структуризации портфеля ЦБ, то страховые компании такой информации при заключении договора не дают, и только по окончании договора сообщают отрицательный результат или в крайнем случае не более $1-2 \%$ от вложенной суммы. Такими мошенническими схемами действуют многие банки, например, КБ «Открытие» и КБ «Альфа-банк».

Другая негативная сторона цифровизации и ее последствий, что цифровая экономика увеличивает риски по изменению многих видов профессий за счет активного воздействия некоторых инструментов цифровизации в виде чат-ботов, блогерства, беспилотных автомобилей, интернет-продажи, фрилансерства и т.д., что в дальнейшем сократит множество нужных профессий - водителей, продавцов, врачей, учителей и др. Увольнение происходит под эгидой сокращение непрофессиональных работников.

На самом деле крупный бизнес стремится выкинуть думающих живых людей из большинства сфер производственной деятельности, чтобы на этом сэкономить. Все переводится в цифровые технологии. Уже сегодня во многих сферах деятельности используются системы с искусственным интеллектом. Например, в медицине определение и нахождение наиболее верного лечения в непредвиденных ситуациях, в сельском хозяйстве, где применяются беспилотные машины, конструкции с помощью компьютерного зрения убирают урожай, дроны используются в борьбе с террористами и т.п. Сегодня элементы искусственного интеллекта применяются во многих компьютерных офисных программах [9].

Искусственный интеллект развивает роботизацию, дрониндустрию, гибкие производственные системы, наносит мощный удар по работникам - специалистам, способных делать те процедуры, которые присущи только человеку, увеличивая востребованность на рынке неквалифицированных работников. Например, при онлайн-торговле через интернет-магазины вовлечено огромное количество курьеров, которые доставляют товары для клиентов-потребителей. Другие категории работников зачастую оказываются выброшенными с предприятий, ненужными по различным причинам, кто по возрасту, кто за правдивые высказывания, которые неугодны для высокооплачиваемого руководства [10].

С внедрением и развитием цифровизации возникают специфические риски, которые ежегодно только возрастают, в особенности, с появлением таких технологий, как: искусственный интеллект, большие данные, блокчейн, криптовалюты, виртуальная реальность и др. Причем риски цифровизации сегодня сознательно умаляются или замалчиваются, стараются их не выпячивать и не обсуждать на международных конференциях, симпозиумах. Зачастую говорят о прекрасных перспективах развития цифровой экономики в будущем, ссылаясь на национальные проекты цифровой экономики, в результате происходит дань моде, идет массовое заимствование западного, чаще ненужного и рискованного. Например, блокчейн, пригодный для узких применений, у нас начинают применять везде, даже в госуправлении. Или искусственному интеллекту решили поручить все сферы деятельности, вплоть до процессов человеческой ответственности - медицина, транспорт, судебная, нотариальная и аудиторская деятельность [11-12].

Следует подчеркнуть, что с расширением цифровизации знатоками и специалистами цифровой экономики вдруг оказались банкиры, гуманитарии, журналисты, которые являются полными дилетантами в сфере информационных технологий, вдруг стали всех обучать цифровому прогрессу, на что ведутся многие ответственные чиновники, депутаты и руководители крупного бизнеса и сразу для внедрения цифровых технологий проводят интерактивные важные совещания, составляются соответствующие бизнес-планы, проводят специальные заседания и конференции по внедрению современных цифровых технологий. И под этим знаменем цифровизации очень многие замечательные отечественные разработки, ноу-хау уходят в другие страны, в США, чаще под востребованными названиями типа Scopus, Web of Science и др. Несомненно, нашим авторам, ученым следует публиковаться в зарубежной печати, однако следует усилить фильтрацию отечественных разработок, если они составляют коммерческую или государственную тайну.

Перечислим основные негативные особенности от реализации цифровых технологий [10].

1. Перебор в заимствовании цифровых западных технологий и вместе с этим деградация собственных компетенций, неактивное создание отечественных разработок, что связано с низкой мотивацией конкретных разработчиков. В России чаще работает принцип «кто делил - тот получил», принцип справедливости давно забыт. В этом лицо «демократического капитализма».

2. Всеобщая реорганизация организационных структур российских компаний под западный 
манер с точки зрения оптимизации управления, оставляя в российских компаниях только специалистов оперативного уровня, а творческий интеллектуальный потенциал сосредотачивается в инновационных центрах транснациональных компаний, в результате прогнозируется отмирание старых профессий и сокращение рабочих мест.

3. Уязвимость, утечка персональных данных, нарушение тайны личной жизни, что может привести в дальнейшем к цифровой зависимости.

4. Риск киберугроз по защите персональных данных и корпоративных данных российских компаний и предприятий, угрозы нарушения суверенитета нашей страны в мировом цифровом пространстве.

5. Захват новых российских рынков (компаний, банков, корпораций) транснациональными компаниями.

6. Увеличение социальной напряженности, потеря рабочих мест, рост безработицы, а с нею и рост преступности.

7. Рост мошеннических схем, в особенности, в страховых компаниях, в банковских структурах, где отношения построены на доверии граждан и слабой юридической защите граждан, снижение качества ответственности со стороны менеджеров.

8. Навязчивая реклама в СМИ, новый цифровой тоталитаризм в основных сферах деятельности.

9. Захват и расширение внешнего управления российской экономики более сильными иностранными игроками. Если цифровая экономика управляется извне, то естественно она и служит в основном иностранным интересам.

10. Появление новых форм преступлений - киберпреступлений, очень низкая степень защищенности со стороны правоохранительных органов, связанной с низкой степенью их компетентности и квалификацией в области цифровых технологий.

11. Слабая юридическая поддержка в борьбе с мошенническими схемами некоторых компаний и корпораций.

12. Повышение степени неравенства при обладании цифровыми информационными ресурсами, возникает поляризация мнений различных групп, активно развивается групповое мышление по интересам.

13. С ростом уровня неопределенности из-за распространения неточной информации, увеличиваются в обществе репутационные риски.

14. Угроза существования человечеству.

Из перечисленных характеристик цифровой экономики выявляются значительные риски, о чем следует задуматься при формировании стратегии и необходимости развития той или иной цифровой технологии. Новые цифровые технологии, которые нам навязывают, зачастую связаны с классическими ложными направлениями.

Навязывание западных цифровых технологий, в том числе с самых высоких трибун приведет к тому, что предприятия вместо производителей, станут потребителями чужих технологий и будем всё более зависимыми от западных цифровых технологий. Важно особенно подчеркнуть опасность построения российской новой экономики на чужой криптовалюте, что может полностью привести к зависимости от цифровых американских технологий.

Согласно новой технологии в области цифровых технологий по «кривой хайпа» возникает пик раскрутки, который обычно составляет 2-3 года. Здесь возникают огромные финансовые затраты на внедрение и адаптацию западных разработок, затем наступает разочарование в низкой эффективности, высокой степени рисков и слабой степени защищенности информации в цифровизации. ИТ-индустрия исследует полученные результаты с практической точки зрения и будут создавать свои собственные разработки на базе своих знаний и компетенций. Средний срок выхода инновационных цифровых новинок на конкретные результаты отечественных разработок, продуктов - 4-6 и более лет. Сегодня не нужно гнаться за модными направлениями западных цифровых технологий, чтобы отчитаться вовремя перед вышестоящим руководством.

Следует на практике использовать следующие положения [12,13]:

1. Следовать не за модными новинками, а исходить от реальных потребностей общества, бизнеса и государства с целью улучшения системы управления и повышения конкурентоспособности.

2. Совершенствовать цифровой суверенитет, как наиболее важное условие внедрения любых технологий.

3. Снизить зависимость от технологического импорта до 10-20\%, что вполне реально при реализации задач импортозамещения в области цифровых технологий.

4. Следует резко увеличивать защиту экономической безопасности на государственном уровне от рисков киберугроз и угроз нарушения суверенитета нашей страны.

Сегодня в базе отечественных разработок есть множество программных продуктов. Есть определенный программный потенциал для разработки больших данных, которые следует использовать и хранить только 
на территории РФ; искусственный интеллект, заказывать интеллектуальные разработки только отечественным университетам и компаниям; интернет вещей и блокчейн нужно контролировать и использовать только отечественные реестры, исключая реестры с внешним управлением [11].

Россия в рейтинге конкурентоспособности цифровой экономики занимает 38 место среди ведущих стран. Для России это неплохие показатели, учитывая многие объективные причины, влияющие на развитие экономики нашей страны. Однако в России есть огромный потенциал по таким показателям, как знания, технологии во многих отраслях, высокий уровень образованности и грамотности, в частности, у взрослого населения [10$11]$.

Учитывая высокий информационный потенциал России, возможности и тенденции развития цифровизации и цифровой трансформации в различных сферах деятельности, можно предположить, что Россия справится с проблемами развития цифровой экономики, и безболезненно сможет внедрить цифровые технологии в повседневную жизнь и установит взаимосвязь с развитием реальной экономики. Развитие цифровой экономики является одним из приоритетных направлений в осуществлении экономического, политического, социального и культурного развития нашей страны [13].

\section{ЛИТЕРАТУРА}

1. Абрамов В.Л. Конкурентоспособность экономики России: современное состояние и стратегия развития // Экономика, статистика и информатика.2012.- №2.- C. 3-7.

2. Антипьев А.Г. 0 путях модернизации экономики и современного российского общества // Труд и соц. отношения. - 2011.— № 1.— С. 3-11.

3. Внуковский Н.И. Тенденции трансформации корпораций с целью повышения их конкурентоспособности // Современная наука: актуальные проблемы теории и практики, Серия «Экономика и право» № 12/2.-2017. - С. 4-8.

4. Внуковский Н.И. Интеллектуально-организационные проблемы в развитии интеллектуальной транспортной системы // Современная наука: актуальные проблемы теории и практики. Серия: Экономика и право. -2020. -№ 01.- С. 16-20.

5. Голиков Ю.А. Экономическая эффективность системы защиты информации: учеб.-метод. пособие / Ю.А. Голиков, Л.Ю. Сульгина.- Новосибирск: СГТА,2012.- $-41 \mathrm{C}$.

6. Глазьев С.Ю. Стратегия опережающего развития России в условиях кризиса. 2010 г.

7. Новая экономическая политика: политика экономического роста. Доклад.- М.: Институт народнохозяйственного прогнозирования PAH, 2013 (http:// www.so-l.ru/news/plist/show/398029).

8. Тимиргалеева Р.Р., Гришин И.Ю., Коротицкая В.В. Риски в условиях развития цифровой экономики России // Научно-методический электронный журнал «Концепт».—2019.— № 6 (июнь).— 0,4 п.л.— URL: http://e-kon-cept.ru/2019/194041.htm.

9. Паспорт национальной программы «Цифровая экономика Российской Федерации» (утв. президиумом Совета при Президенте Российской Федерации по стратегическому развитию и национальным проектам 24 декабря 2018 г. N16)

10. Развитие цифровой экономики в России. Программа до 2035 года. [Электронный ресурс] http://innclub.info/wpcontent/uploads/strategy.pdf

11. Сажина, М.А. Блокчейн в системе управления знанием: монография / М.А. Сажина, С.В. Костин.— М.: ИД «ФОРУМ»: ИНФРА-М, 2019.— 90 с.— (Научная мысль)

12. World Digital Competitiveness Ranking. IMD. 2019. P. 26-29 Available at: https://www.imd.org/wcc/world-competitiveness-center-rankings/world-digitalcompetitiveness-rankings-2019/ (accessed 17 December 2019).

13. Что такое цифровая экономика? Тренды, компетенции, измерение: докл. кXX Апр. междунар. науч. конф. по проблемам развития экономики и общества, Москва, 9-12 апр. 2019 г. / Г.И. Абдрахманова, К.0. Вишневский, Л.М. Гохберг и др.; науч. ред. Л.М. Гохберг; Нац. исслед. ун-т «Высшая школа экономики».—- М.: Изд. дом Высшей школы экономики, 2019. - 82 с.

( ) Внуковский Николай Иванович ( vnukovsk@ya.ru ).

Журнал «Современная наука: актуальные проблемы теории и практики» 